Gary F. Morris MD, Wendy Gore-Hickman MD FRCPC, Scott A. Lang MD FRCPC, Raymond W. Yip MD FRCPC

\title{
Can parturients distinguish between intravenous and epidural fentanyl?
}

\begin{abstract}
We tested the hypothesis that the sedative, euphoric, and analgesic effects of intravenous fentanyl would distinguish intravenous from epidural administration. One hundred ASA I and II labouring parturients received $100 \mu \mathrm{g}$ fentanyl either iv or via an epidural catheter in a double-blind, randomized, crossover fashion. Nineteen anaesthetists (8 staff and 11 residents) participated and correctly guessed the route of administration of the fentanyl in 61/66 intravenous doses and in 69/75 epidural doses yielding a sensitivity of $92.4 \%$, a specificity of $92.0 \%$, a positive predictive value of $91.0 \%$, and a negative predictive value of $93.2 \%$. Of the 41 patients that were crossed over, 38 (92.7\%) were able to detect a difference between the routes of administration. Most patients experienced prompt, short-lived symptoms with iv fentanyl but no important differences in fetal heart rate pattern or in maternal desaturation were seen between the groups. This study suggests that subjective symptoms will accurately distinguish intravenous from epidural fentanyl administration in labouring parturients $(P<0.001)$, and should serve as a safe and reliable intravenous test dose for epidural anaesthesia in the obstetric population.
\end{abstract}

Nous avons vérifié l'hypothèse selon laquelle les effets sédatifs, euphorisants et analgésiques du fentanyl intraveineux différencieraient l'administration intraveineuse de l'épidurale. Cent parturientes en travail ASA I et II ont reçu du fentanyl $100 \mu \mathrm{g}$ soit par la voie veineuse, soit par un cathéter épidural, au hasard et en test croisé à double inconnue. Dix-neuf anesthé-

\section{Key words}

ANAESTHESIA: obstetric;

ANALGESICS: fentanyl;

ANAESTHETIC TECHNIQUE: epidural.

\footnotetext{
From the Department of Anaesthesia, Royal University

Hospital, University of Saskatchewan, Saskatoon,

Saskatchewan S7N 0X0.

Address correspondence to: Dr. Gary F. Morris, Department of Anaesthesia, Royal University Hospital, University of

Saskatchewan, Saskatoon, Saskatchewan S7N 0X0.

Accepted for publication 28th April, 1994.
}

sistes (huit patrons et onze résidents) ont participé à l'étude et ont identifié correctement la voie d'administration du fentanyl dans 61 sur 66 doses intraveineuses et dans 69 sur 75 doses épidurales produisant une sensibilité de $92,4 \%$, une spécificité de $92,0 \%$, une valeur prédictive positive de $91,0 \%$ et une valeur prédictive négative de 93,2\%. Des 41 patientes en croisement, $83(92,7 \%)$ ont été capables de déceler la différence entre les voies d'administration. La plupart des patientes ont éprouvé des symptômes immédiats et de courte durée avec le fentanyl iv mais nous niavons pas constaté de différences sur le tracé de la fréquence foetale et pour le degré de désaturation maternelle entre les groupes. Cette étude porte à croire que les symptômes subjectifs permettent de distinguer avec précision l'administration intraveineuse de ladministration épidurale chez les patientes en travail $(P<0,001)$ et devrait servir de dose-test fiable et sans danger pour l'anesthésie épidurale de la parturiente.

It has become generally accepted that a test dose should precede epidural anaesthesia to ensure that a bolus of anaesthetic solution will not be deposited either intravenously or intrathecally. ${ }^{1}$ While local anaesthetics are generally used to detect intrathecal administration, considerable discussion continues with regard to a test dose that will safely, reliably, and promptly detect intravascular injection. ${ }^{2-4}$ Various techniques have been suggested, ${ }^{5-9}$ but, serious concerns ${ }^{10-14}$ have precluded the establishment of a "gold standard" for this test.

Subjective symptoms are frequently noted in patients receiving intravenous opioids. Freeman and Hicks ${ }^{15}$ observed such symptoms associated with the injection of fentanyl into an epidural catheter, suggesting an intravascular injection in their patient. Further testing with epinephrine produced a positive chronotropic response and prompted replacement of the catheter. These observations were confirmed by Yoshii et al. ${ }^{16}$ However, they provided only indirect data regarding the ability of anaesthetists to predict intravascular injections. We sought to test the accuracy and reliability of the subjective symptoms associated with the administration of fentanyl. Further, we assessed the ability of anaesthetists to distinguish 
correctly between epidural and intravenous administration of fentanyl in labouring parturients.

\section{Methods}

Following approval from the University of Saskatchewan Advisory Committee on Ethics in Human Experimentation and with written informed consent, one hundred ASA I and II labouring parturients requesting epidural analgesia were enrolled into two groups in a prospective, randomized, double-blind, crossover trial. There were no specific exclusion criteria apart from drug allergy. $\mathrm{Pa}-$ tients in labour considered suitable for epidural analgesia were eligible to be enrolled. Parturients who had not delivered two hours after the initial assessment, were crossed over to the alternate group.

One group received $100 \mu \mathrm{g}$ fentanyl $i v$ and saline via an epidural catheter, the other received saline $i v$ and 100 $\mu \mathrm{g}$ fentanyl via the epidural catheter. Two $3 \mathrm{ml}$ syringes were prepared by the anaesthetist. The first was prepared with $100 \mu \mathrm{g}$ fentanyl in a volume of $2 \mathrm{ml}$ and labeled "fentanyl." The second syringe was filled with $2 \mathrm{ml}$ of preservative-free, $0.9 \%$ saline and remained unlabelled. These syringes, together with labels enclosed in a randomization envelope, were given to an attending nurse who then relabelled the syringes, "epidural" or "intravenous," according to instructions within the envelope.

After intravenous access was secured, and a fluid bolus of one litre Ringer's lactate administered, baseline measurements of blood pressure, pulse, and oxygen saturation were recorded using a Dinamap 1846 SX vital signs monitor. The level of maternal distress was assessed by the attending anaesthetist according to one of four categories: none; mild; moderate; severe. The fetal heart rate was recorded continuously with a Hewlett Packard 8040A tococardiograph. A lumbar epidural catheter was placed in a manner determined by the individual anaesthetist, and secured to the patient. This catheter was then tested with $45 \mathrm{mg}$ lidocaine $1.5 \%$ combined with $15 \mu \mathrm{g}$ epinephrine, which is the usual practice in our institution. Once satisfied that the catheter was appropriately positioned, the blinded study syringes were administered simultaneously, the "intravenous" into a rapidly flowing intravenous line and the "epidural" via the epidural catheter.

Presence or absence of subjective symptoms was recorded in each of four categories: sedation; dizziness or lightheadedness; euphoria; analgesia. These specific subjective assessments, together with measurements of maternal and fetal vital signs, were recorded each minute for the first five minutes, then every five minutes for a total of $30 \mathrm{~min}$. Without the aid of specific criteria to interpret symptomatology, the anaesthetist recorded a
TABLE I Demographic data

\begin{tabular}{lccl}
\hline Characteristic & $\begin{array}{l}\text { Intravenous } \\
(n=50)\end{array}$ & $\begin{array}{l}\text { Epidural } \\
(n=50)\end{array}$ & \\
\hline Age & $27.4 \pm 4.9 \mathrm{yr}$ & $26.2 \pm 5.2 \mathrm{yr}$ & NS \\
Height & $163.4 \pm 6.8 \mathrm{~cm}$ & $164.7 \pm 6.3 \mathrm{~cm}$ & NS \\
Weight & $74.6 \pm 13.4 \mathrm{~kg}$ & $78.2 \pm 12.3 \mathrm{~kg}$ & NS \\
Parity & & & \\
- Nulliparous & $24(48 \%)$ & $26(52 \%)$ & NS \\
- Primiparous & $12(24 \%)$ & $13(26 \%)$ & NS \\
- Multiparous & $14(28 \%)$ & $11(22 \%)$ & NS \\
Race & & & \\
- Caucasian & $37(74 \%)$ & $39(78 \%)$ & NS \\
- N. American Indian & $11(22 \%)$ & $8(16 \%)$ & NS \\
- Other & $2(4 \%)$ & $3(6 \%)$ & NS \\
\hline
\end{tabular}

Data expressed as mean $\pm \mathrm{SD}$.

NS $=$ not significant.

"guess" as to whether or not this patient had received iv fentanyl.

Following the first five minutes of assessment, the anaesthetist established epidural analgesia with a local anaesthetic solution of their preference. No additional narcotics were to be administered. At two hours, those patients who had not yet delivered were crossed over to the alternate arm, and received the study medications via the other route. In a manner similar to the initial assessment, blinded syringes were administered, observations recorded, and a "guess" entered by an attending anaesthetist. Upon completion, the patient was asked to comment on her level of satisfaction with participation in the study, and if crossed over, whether she noted any difference between the two trials.

Continuous data were analyzed using a two-tailed independent $\mathbf{t}$ test. Categorical data were analyzed using $\chi^{2}$ test, with $P<0.05$ set as the level of significance for all inferential tests. A receiver operating characteristic (ROC) curve was constructed to present the accuracy of this fentanyl diagnostic test by plotting the true positive rate (sensitivity) on the vertical axis against the false positive rate (1-specificity) on the horizontal axis. Each observation period is represented by a distinct point that depicts the concurrent measure of both sensitivity and specificity.

\section{Results}

One hundred ASA I and II labouring parturients were enrolled, and of these 41 crossed over to receive fentanyl via the alternate route. There were no differences between the groups at initial randomization with regard to age, height, weight, parity, or racial origin (Table I). In addition, prior to study enrollment the groups were similar with respect to technique of epidural placement, level of 
TABLE II Baseline characteristics prior to study enrollment

\begin{tabular}{lccc}
\hline Characteristic & $\begin{array}{l}\text { Intravenous } \\
(n=50)\end{array}$ & $\begin{array}{l}\text { Epidural } \\
(n=50)\end{array}$ & \\
\hline Distress & & & \\
- None/mild & $9(18 \%)$ & $8(16 \%)$ & NS \\
- Moderate & $32(64 \%)$ & $29(58 \%)$ & NS \\
- Severe & $9(18 \%)$ & $13(26 \%)$ & NS \\
Sedatives/narcotics & $9(18 \%)$ & $8(18.7 \%)$ & NS \\
\hline
\end{tabular}

NS $=$ not significant.

distress, previous analgesia, and frequency of detectable intravascular placement (Table II). All seven of the epidural catheters placed intravascularly, as assessed by blood in the epidural catheter, were repositioned before testing. In no instance was an occult intravascular placement detected using a lidocaine/epinephrine test dose or with evidence of local anaesthetic toxicity. Satisfactory epidural analgesia was established in all patients.

Following the administration of fentanyl there were no differences in maternal blood pressure, pulse, or fetal heart rate monitor recording, but those patients who received $i v$ fentanyl demonstrated a lower oxygen saturation than those in the epidural group within the first five minutes after injection $(P<0.01)$, and this difference persisted throughout the remainder of the study period (Table III). Two patients in the intravenous group and one in the epidural group required supplemental oxygen for either maternal desaturation or for fetal decelerations seen during the period of observation. This did not represent a difference between the groups.

The pattern of the recorded symptoms of sedation or dizziness compared with those for dizziness alone following the administration of intravenous or epidural fentanyl is displayed in Figure 1. Of the 41 patients crossed over, $38(92.7 \%)$ noted a subjective difference between the two routes of administration. No patient requested to withdraw from the study, and in no case was dysphoria or dissatisfaction noted.

Further analysis demonstrated dizziness to be the most distinct discriminator for the intravenous injection of fentanyl. Though not as sensitive as employing all symptoms in combination, the presence of dizziness within the first five minutes was strongly indicative of intravascular fentanyl, with few observations spuriously suggesting $i v$ fentanyl when it had been given by the epidural route (Figure 1). The clustering of the observations from two to five minutes near the upper left corner of the ROC curve (Figure 2), defines observations with a high degree of both sensitivity and specificity. Observations made after five minutes demonstrate a marked loss of sensitivity.

Nineteen anaesthetists participated in the assessment portion of the study; eleven residents at various levels
TABLE III Assessment

\begin{tabular}{|c|c|c|c|}
\hline Characteristic & $\begin{array}{l}\text { Intravenous } \\
(n=50)\end{array}$ & $\begin{array}{l}\text { Epidural } \\
(n=50)\end{array}$ & \\
\hline \multicolumn{4}{|l|}{ BP systolic } \\
\hline - Initial & $129 \pm 18 \mathrm{mmHg}$ & $128 \pm 20 \mathrm{mmHg}$ & NS \\
\hline$-3 \min$ & $124 \pm 16 \mathrm{mmHg}$ & $122 \pm 17 \mathrm{mmHg}$ & NS \\
\hline$-5 \min$ & $122 \pm 15 \mathrm{mmHg}$ & $121 \pm 15 \mathrm{mmHg}$ & NS \\
\hline$-30 \mathrm{~min}$ & $123 \pm 15 \mathrm{mmHg}$ & $121 \pm 13 \mathrm{mmHg}$ & NS \\
\hline \multicolumn{4}{|l|}{ Pulse } \\
\hline - Initial & $85 \pm 13 \mathrm{bpm}$ & $89 \pm 10 \mathrm{bpm}$ & NS \\
\hline$-3 \min$ & $87 \pm 13 \mathrm{bpm}$ & $91 \pm 9 \mathrm{bpm}$ & NS \\
\hline$-5 \min$ & $87 \pm 13 \mathrm{bpm}$ & $91 \pm 9 \mathrm{bpm}$ & NS \\
\hline$-30 \mathrm{~min}$ & $83 \pm 14 \mathrm{bpm}$ & $85 \pm 13 \mathrm{bpm}$ & NS \\
\hline \multicolumn{4}{|l|}{$\mathrm{O}_{2}$ saturation } \\
\hline - Baseline & $97.1 \pm 1.7 \%$ & $97.3 \pm 1.9 \%$ & NS \\
\hline$-0-5 \min$ & $96.2 \pm 2.2 \%$ & $97.3 \pm 1.8 \%$ & $P<0.01$ \\
\hline$-5-30 \mathrm{~min}$ & $96.5 \pm 1.8 \%$ & $97.1 \pm 1.8 \%$ & $P<0.01$ \\
\hline \multicolumn{4}{|l|}{ Fetal heart rate } \\
\hline \multicolumn{4}{|l|}{ Apgar } \\
\hline$-1 \mathrm{~min}$ & $7.5 \pm 1.4$ & $7.7 \pm 0.9$ & NS \\
\hline$-5 \min$ & $8.8 \pm 0.8$ & $9.0 \pm 0.7$ & NS \\
\hline
\end{tabular}

Data expressed as mean $\pm \mathrm{SD}$.

NS $=$ not significant.

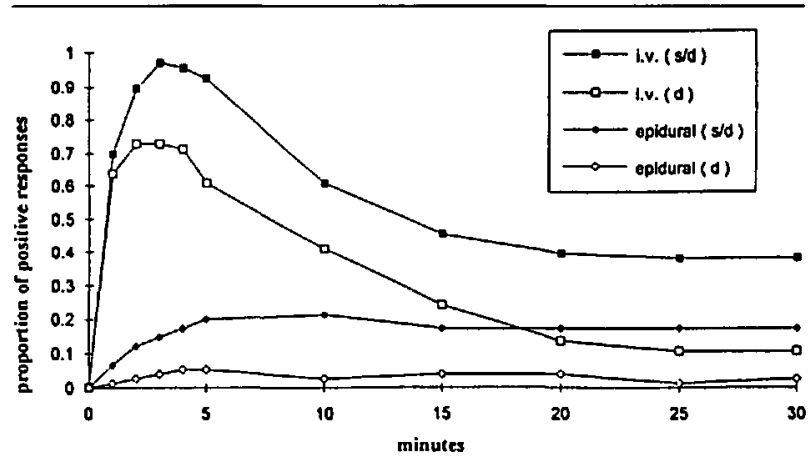

FIGURE 1 Sedation or dizziness versus dizziness alone in response to fentanyl. Proportion of parturients declaring symptoms of sedation or dizziness (s/d) in response to fentanyl administration in contrast to those patients assessed only for dizziness alone (d).

of training, and eight staff. They were directed only in regard to the data that were to be collected. No instruction was provided regarding the criteria necessary for determining a positive response. Personal observations gleaned from previous experience in the administration of opioid medication to patients appeared to serve as the basis for the "guess" recorded by the anaesthetist. The participating anaesthetist correctly identified intravenous fentanyl in 61 of 66 patients (50 initial plus 16 crossover), and epidural administration in 69 of the 75 patients (50 initial plus 25 crossover) receiving fentanyl via that route. The administration of $i v$ fentanyl based upon the assessment of 


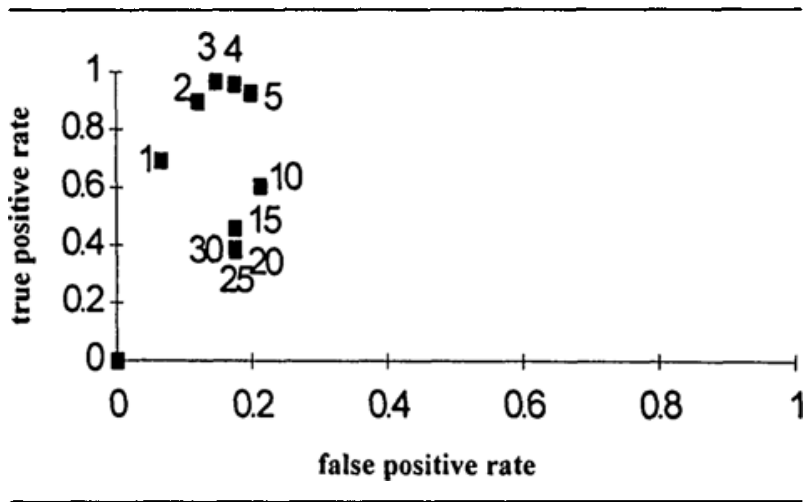

FIGURE 2 Receiver operating characteristic curve utilizing sedation or dizziness as a predictor of intravascular placement. A plot of the true positive rate (sensitivity) versus the false positive rate (1-specificity) at $1,2,3,4,5,10,15,20,25$ and 30 minutes utilizing sedation or dizziness as end-points for detection of intravenous fentanyl injection. The clustering of points in the upper left demonstrate those periods of both high sensitivity and specificity (i.e., best cut-off point for making clinical decisions). The decline in the true positive rate following the five minute assessment indicates a decline in sensitivity after this point (i.e., the positive predictive value of fentanyl as a test dose declines).

the anaesthetist yielded results of: sensitivity $92.4 \%$; specificity $92.0 \%$; positive predictive value $91.0 \%$; negative predictive value $93.2 \%$.

\section{Discussion}

Unintentional intravascular placement of epidural catheters has been reported to occur with a frequency between 2 and $9 \%,{ }^{6,17-19}$ and may be associated with serious outcomes. ${ }^{17,20,21}$ Most episodes of intravascular placement are detected by noting the presence of blood in the catheter with aspiration, as was noted in all seven instances in this study. It is for those catheters in which blood is not apparent that a test dose is required for identification. ${ }^{12}$

Studies evaluating test doses have been limited by the ability to attain an acceptable level of sensitivity and specificity, or have been associated with specific hazards or limitations to widespread use. ${ }^{5-9,22,23}$ There is concern about the safety of epinephrine in parturients with preeclampsia, and to the accuracy of its use in those patients currently receiving $\beta$-blocking medications. ${ }^{3-5,14}$ Precordial Doppler assessment for venous air embolism has been used as the basis of a test dose for intravascular placement of the epidural catheter. ${ }^{6}$ However, the special equipment and expertise required with the use of this technique will likely limit its widespread application. Furthermore, there are theoretical concerns regarding maternal and fetal safety when air is used. ${ }^{13,24}$ The sole use of lidocaine to demonstrate intravascular placement is dependent on demonstration of early symptoms of local anaesthetic toxicity. ${ }^{9}$ Patient safety may become a concern as the use of a fixed $100 \mathrm{mg}$ dose may elicit more serious effects of local anaesthetic toxicity in some parturients. In addition, should this entire amount be deposited intrathecally, an unacceptably high level of anaesthesia may result.

We demonstrated a great variation in individual response to a bolus of intravenous fentanyl in labouring patients. Most patients experienced prompt, definite, short-lived symptoms of sedation, dizziness or lightheadedness. Others declared symptoms that were much more subtle, yet, when directly questioned, even these subjects recognized a sensorial difference following administration of fentanyl intravenously. Patient acceptance was excellent. Despite impressive symptoms in many patients receiving $i v$ fentanyl, the experience was not perceived as unpleasant.

A rapid change in the level of analgesia would be a useful measure of intravascular placement only before the establishment of epidural anaesthesia, or for those patients with inadequate analgesia. Euphoria proved to be a difficult measure to assess. These symptoms were therefore not clinically useful when considered in isolation and did not improve predictive values even when combined with symptoms of sedation or dizziness.

Demonstration of an early appearance of symptoms of sedation or dizziness supports the findings of Yoshii et al. ${ }^{16}$ In contrast, the period of observation in our study was expanded from three to $30 \mathrm{~min}$. It becomes evident that a difference between routes of administration becomes less distinct as these symptoms are followed over time (Figure 1). This pattern characterized by a prompt onset of symptoms followed by a rapid decrease in intensity has been demonstrated in pharmacokinetic studies of intravenous fentanyl in other patient populations. ${ }^{25,26}$

It is essential that blinded observers not only note the presence or absence of symptoms, but that their interpretation of these symptoms facilitate appropriate clinical decisions. We have demonstrated that anaesthestists at various levels of training were able to interpret subjective symptoms and to determine correctly the route of fentanyl administration accurately $92.4 \%$ of the time. Some of the errors of interpretation arose from assessments of patients reporting such mild sedation or dizziness that it was felt unlikely to be due to iv fentanyl. Any increased sedation or dizziness within the first five minutes after a fentanyl test dose should be interpreted as a positive response for intravascular injection. Greater experience with the pattern of symptoms exhibited after receiving intravenous and epidural fentanyl may allow anaesthetists to improve further their accuracy of prediction.

Fentanyl has been used extensively in obstetrics, ${ }^{27}$ and has been shown to be safe when given intravenously to labouring parturients, ${ }^{28,29}$ with little depression of mother or infant. In studies of labouring women receiving a variety of systemic analgesics ${ }^{30,31}$ a degree of arterial desat- 
uration was noted, yet no correlation with adverse fetal outcome was observed. Similarly, we were unable to demonstrate a difference in fetal outcome between the groups. We did demonstrate maternal desaturation in the group receiving $i v$ fentanyl compared with those in whom the fentanyl was administered via an epidural catheter. This difference in maternal oxygen saturation was not clinically significant with the doses of fentanyl used in this study (the difference in the means for each group was $<1 \%$ ). Two patients in the intravenous group and one in the epidural group received supplemental oxygen for either persistent desaturation or fetal deceleration during the 30-min study period, which is similar to levels of desaturation seen in parturients receiving no analgesia in labour. ${ }^{31}$ Parturients may demonstrate serious desaturation whether or not systemic analgesics are administered. The apparent safety of $i v$ fentanyl should certainly not decrease the level of vigilance while attending these patients through labour and delivery.

Many obstetric anaesthetists routinely use epidural fentanyl, by bolus or continuous infusion in conjunction with a local anaesthetic solution. ${ }^{27,32}$ Fentanyl has been used in combination with local anaesthetics in the subarachnoid space for both labour analgesia and for Caesarean section. ${ }^{27,33}$ Despite subarachnoid administration of fentanyl in doses up to $50 \mu \mathrm{g}$ without evidence of serious adverse maternal or neonatal effects, ${ }^{33}$ fentanyl has not been demonstrated to be useful as an intrathecal test dose. Two separate test doses should be employed. Little additional time is required when the fentanyl test dose follows a test with local anaesthetic. This practice will also minimize the risk of depositing fentanyl unintentionally into the subarachnoid space. The safe use of fentanyl in various settings for obstetric anaesthesia has been established, and provides a degree of confidence that neither the parturient nor her fetus will be exposed to increased risk should this dose be deposited intravascularly, intrathecally or within the epidural space.

In conclusion, we have demonstrated that parturients can distinguish intravenous from epidural fentanyl with a high degree of sensitivity and specificity. By exploiting a drug commonly used in obstetric anaesthesia, in conjunction with a series of simple questions, anaesthetists can safely and reliably detect intravascular injection. We conclude that fentanyl is suitable as a test dose for intravascular placement of an epidural catheter in labouring parturients.

\section{References}

1 Shnider SM, Levinson G, Ralston DH. Regional anesthesia for labor and delivery. In: Shnider SM, Levinson G (Eds.). Anesthesia for Obstetrics. 3rd ed. Baltimore: Williams \& Wilkins, 1993: 137-41.
2 Biehl DR. The dilemma of the epidural test dose (Editorial). Can J Anaesth 1987; 34: 545-8.

3 Dain SL, Rolbin SH, Hew EM. The epidural test dose in obstetrics: is it necessary? Can J Anaesth 1987; 34: 601-5.

4 Prince $G, M c G r e g o r ~ D$ Obstetric epidural test doses. A reappraisal. Anaesthesia 1986; 41: 1240-50.

5 Moore DC, Batra MS. The components of an effective test dose prior to epidural block. Anesthesiology 1981; 55: 693-6.

6 Leighton BL, Norris MC, DeSimone CA, Rosko T, Gross $J B$. The air test as a clinically useful indicator of intravenously placed epidural catheters. Anesthesiology 1990; 73: 610-3.

7 Cherala $S R$, Mehta $D$, Greene $R$. Ephedrine as a marker of intravascular injection in labouring parturients. Reg Anesth 1990; 15: 15-8.

8 Leighton $B L$, DeSimone $C A$, Norris $M C$, Chayen $B$. Isoproterenol is an effective marker of intravenous injection in laboring women. Anesthesiology 1989; 71: 206-9.

9 Colonna-Romano P, Lingaraju N, Braitman LE. Epidural test dose: lidocaine $100 \mathrm{mg}$, not chlorprocaine, is a symptomatic marker of $\dot{w}$ injection in labouring parturients. Can $\mathrm{J}$ Anaesth 1993; 40: 714-7.

10 Leighton BL, Norris $M C$, Sosis $M$, Epstein R, Chayen B, Larijani $G E$. Limitation of epinephrine as a marker of intravascular injection in laboring women. Anesthesiology 1987; 66: 688-91.

11 Cartwright PD, McCarroll SM, Antzaka C. Maternal heart rate changes with a plain epidural test dose. Anesthesiology 1986; 65: 226-8.

12 McLean BY, Rottman RL, Kotelko DM. Failure of multiple test doses and techniques to detect intravascular migration of an epidural catheter. Anesth Analg 1992; 74: 454-6.

13 Sethna $N F$, Berde $C B$. Venous air embolism during identification of the epidural space in children (Editorial). Anesth Analg 1993; 76: 925-7.

14 Hood DD, Dewan DM, James FM III. Maternal and fetal effects of epinephrine in gravid ewes. Anesthesiology 1986; 64: 610-3.

15 Freeman $A B$, Hicks $L$. Epidural fentanyl as a test dose (Letter). Anesth Analg 1989; 68: 187-8.

16 Yoshii WY, Kotelko DM, Rasmus KT, et al. Fentanyl for intravascular test dose in obstetrics. Regional Anesthesia 1993; 18: 296-9.

17 Naulty JS, March MG, Leavitt KL, Smith R, Altstatt A, Urso $P R$. Effect of changes in labor analgesic practice on the safety and efficacy of epidural anesthesia. Anesthesiology 1992; 77: A983.

18 Verniquet $A J W$. Vessel puncture with epidural catheters. Experience in obstetric patients. Anaesthesia 1980; 35: 660-2.

19 Kenepp NB, Gutsche BB. Inadvertent intravascular injec- 
tions during lumbar epidural anesthesia (Letter). Anesthesiology 1981; 54: 172-3.

20 Albright GA. Cardiac arrest following regional anesthesia with etidocaine or bupivacaine (Editorial). Anesthesiology 1979; 51: 285-7.

21 Marx GF. Cardiotoxicity of local anesthetics - the plot thickens (Editorial). Anesthesiology 1984; 60: 3-5.

22 Colonna-Romano P, Lingaraju N, Godfrey SD, Braitman $L E$. Epidural test dose and intravascular injection in obstetrics: sensitivity, specificity, and lowest effective dose. Anesth Analg 1992; 75: 372-6.

23 Leighton $B L$, Norris $M C$. Epidural test dose and intravascular injection in obstetrics: sensitivity, specificity (Letter). Anesth Analg 1993; 76: 1174.

24 Naulty JS, Ostheimer GW, Datta S, Knapp R, Weiss JB. Incidence of venous air embolism during epidural catheter insertion. Anesthesiology 1982; 57: 410-2.

$25 \mathrm{McClain} D A$, Hug CC Jr. Intravenous fentanyl kinetics. Clin Pharmacol Ther 1980; 28: 106-14.

26 Gourlay GK, Murphy TM, Plummer JL, Kowalski SR, Cherry DA, Cousins MJ. Pharmokinetics of fentanyl in lumbar and cervical CSF following lumbar epidural and intravenous administration. Pain 1989; 38: 253-9.

27 Hughes SC. Intraspinal opiates in obstetrics. In: Shnider SM, Levinson G (Eds.). Anesthesia for Obstetrics. 3rd ed., Baltimore: Williams \& Wilkins, 1993; 163-85.

28 Rayburn W, Rathke A, Leuschen P, Chleborad J, Weidner $W$. Fentanyl citrate analgesia during labor. Am J Obstet Gynecol 1989; 161: 202-6.

29 Rayburn WF, Smith CV, Parriott JE, Woods RE. Randomized comparison of meperidine and fentanyl during labor. Obstet Gynecol 1989; 74: 604-6.

30 Deckardt R, Fembacher PM, Schneider KTM, Graeff $H$. Maternal arterial oxygen saturation during labor and delivery: pain-dependent alterations and effects on the newborn. Obstet Gynecol 1987; 70: 21-5.

31 Porter KB, O'Brien WF, Kiefert V, Knuppel RA. Evaluation of oxygen desaturation events in singleton pregnancies. J Perinatol 1992; 12: 103-6.

32 Vella LM, Willatts DG, Knott C, Lintin DJ, Justins DM, Reynolds $F$. Epidural fentanyl in labour. An evaluation of the systemic contribution to analgesia. Anaesthesia 1985; 40: 741-7.

33 Hunt CO, Naulty JS, Bader AM, et al. Perioperative analgesia with subarachnoid fentanyl-bupivacaine for cesarean delivery. Anesthesiology 1989; 71: 535-40. 